\title{
Robotics in the Modern World of Work - Results From an Empirical Study Regarding Business Ethics
}

\author{
Daniela Ludin, Wanja Wellbrock*, Erika Müller, Wolfgang Gerstlberger, Lea Gray, Sabrina Salat
}

\begin{abstract}
The digital revolution is changing the world. Robots, big data and artificial intelligence are the key technologies of the future and the basis of important innovations for the future development of the economy and society. In companies, this fact requires strategic rethinking and adjustments in ever-shorter time cycles. The creation of an agile and collaborative production to achieve the goals is often a basic requirement. With adaptation to technical progress, requirements and goals change continuously. To be and remain competitive, companies are forced to have at least the same technological standard as their competitors. In order to meet these challenges today, the use of highly efficient mechatronic systems such as robots is necessary. The paper analyses business ethics relevant aspects of robotics by using a survey with 88 respondents.
\end{abstract}

Keywords: business ethics; digitalization; ethics; robotics; sustainability

\section{INTRODUCTION}

The fourth industrial revolution is progressing inexorably and is bringing major global and disruptive changes with regard to technologies in use and level of knowledge needed $[6,33,35]$. The progressive use of artificial intelligence (AI), robots, the Internet of Things and Big Data is changing familiar work processes, and might lead to automation of industrial production processes, services and even creative activities [6]. Increasing globalisation is accompanied by the networking of systems and data and vice versa. Among other things, this results in an increased need for communication and information [26].

The speed of this technological revolution is expected to challenge economies and societies [6]. Technological developments linked to computerisation, automation and technological advancement are at the forefront [24]. In companies, this fact requires strategic rethinking and adjustments in ever-shorter time cycles. The creation of an agile and collaborative production to achieve the settled goals is often a basic requirement. With adaptation to technical progress, requirements and goals change continuously. To be and remain competitive, companies are forced to have at least the same technological standard as their competitors. In order to meet these challenges and to stay competitive, the use of highly efficient mechatronic systems such as AI and robots needs to be considered [12]. In addition to the many opportunities associated with this, the impacts of AI and robotics especially on human labour are still uncertain and must be weighed up [6, 11, 12, 24, 26, 33]. Positive impacts might relate e.g. to creation of new jobs, higher productivity and flexibility as well as reduced costs. In addition, the improvement of health and life quality are viewed as a positive effect of using robots especially in routinedominated or dangerous work places $[16,36]$. On the other hand, replacement of human labour especially of untrained workers by $\mathrm{AI}$ and robots as well as an increase in income equality are seen as the biggest threats $[6,11,24,26]$.

Benefits and threats of a wider use of AI and robotics may differ related to firm size, sector- and country-specific aspects $[11,22,26]$. This complex interaction needs further investigation in order to identify necessary steps to adapt production processes, training of workers or even political framework conditions to support positive and mitigate negative effects [8]. This paper aims to contribute to research on the influence of robotics on human labour in the German context by combining the perspectives of business ethics, mechatronics, production management and human resource management. A questionnaire was used to collect empirical data from employees working in different sectors. The aim is to examine the fields of application, chances and risks as well as the future development of robotics both in a theoretical and in an empirical way.

An additional goal is to find out the extent to which robotics is already prevalent in the working world and to what extent employees are included and informed into ongoing transformation processes. It is also important to find out how willing people are to collaborate with robots in their working environment and what might be further impacts of robots on humans. This refers to activities, requirements as well as the personal perception of employees, which is to be estimated by the answers of the interviewees.

\section{METHODOLOGY}

A literature analysis and a fully structured survey are used as basic methods for this study. For the literature review, research texts, working papers and contributions of various authors found and selected were examined and evaluated based on the central problems and questions, which have to be answered in this paper [37].

In empirical social research, a survey is the most diverse and most frequently applied method to collect and analyse data and elaborate on specific topics [23, 32].

A written consultation based on a fully structured questionnaire with partially open questions was carried out to collect empirical data. This questionnaire was created via an online survey portal and distributed via email or directly as a link in order to reduce time and costs for data collection and to allow scalability. Open questions are included in the 
sense of a partially standardized survey in order to record qualitative results and to give the respondents more leeway to answer [4]. The responses received were analysed using simple statistical methods. Answers to open questions were included in the evaluation in a qualitative way.

\section{THEORETICAL BACKGROUND 3.1 Fields of Science}

The subject of this study in the field of economic and social research is investigated by combining business ethics, mechatronics, production management and human resources into a theoretical framework (cf. Fig. 1).

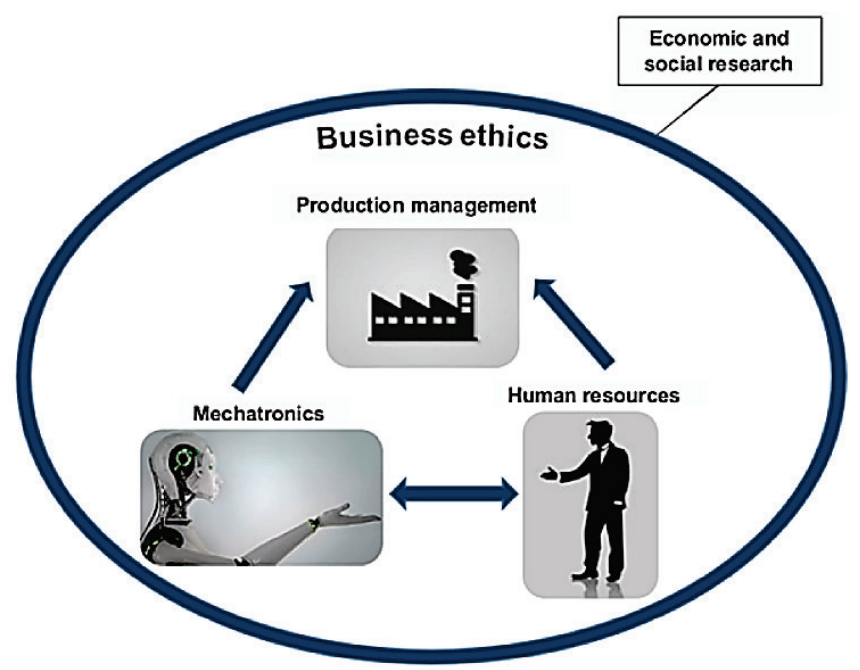

Figure 1 Classification in Science (own illustration)

\subsection{Theoretical Background on Business Ethics}

Business ethics is a branch of applied ethics and deals with the question how moral regulations and behaviour can and must be in a modern economic system. Business ethics is subdivided in ethical aspects of companies, individuals, orders and consumption [2,27].

It is, among other things, influenced and guided by the actions of different individuals. Over time, three systems of standards have developed - conventions, morals and law. Conventions are well-established rules in society and are described as "can-be" expectations. In contrast, the moral rules by which actions are evaluated are only right or wrong. They represent "target expectations". Legal norm systems are "must expectations" which must be adhered to under all circumstances and are relatively easy to check.

Business ethics is also divided into various levels of analysis: meta, normative, applied and descriptive ethics. Meta ethics is concerned with the question of ethical or moral judgement itself, for example, under what conditions a fact is judged right or wrong. Normative ethics deals with the question of how one should act morally and has the goal of analysing and evaluating moral norms and deriving possible solutions from them. Based on this, applied ethics provides concrete recommendations for action in specific situations. Existing systems of moral rules are described and explained by descriptive ethics. In contrast to meta and normative ethics, descriptive ethics is based on empirical methods [2, 27].

The fields of action of business ethics are broad and include education, environmental protection, working conditions and human rights.

In everyday business life, many different interest groups are whose demands must be met. There is the difficulty of finding the right balance in the conflict between entrepreneurial success and compliance with self-imposed or legally prescribed guidelines. In business practice, the abovementioned relationships are often reflected in a code of conduct or, in some areas, in compliance guidelines [9].

The term "machine ethics" reflects a still relatively new sub-area in practice and increasingly subject of operational considerations. At its core, it is concerned with the moral behaviour of machines towards human users and perhaps other machines. Machine ethical questions might be e.g. related to the use of partially or fully autonomous programs and systems such as robots. In concrete terms, the focus is on topics such as safety, job loss and decision-making power of machines as well as necessary regulations is concerned with ensuring that the behavior of machines toward human users, and perhaps other machines as well, is ethically acceptable $[1,9]$. Research around machine ethics also deals with possible risks that might arise from "future greater-thanhuman intelligence machines". In particular, intelligent robots or AI technology might challenge human abilities to understand or regulate machine behaviour, which might lead to negative feelings or trust issues or other reservations among workers [9].

\subsection{Theoretical Background on Mechatronics}

The fourth industrial revolution results in progressive digitalization, globalization and automation. Mechatronic systems represent essential key technologies and thus also the linkage of human with machine capabilities. In 1969, a Japanese developer coined the term "mechatronics". It is composed of the fields of mechanical engineering, electronics and electrical systems for information processing by using intelligent computer control elements (IT technology). These systems find application in various production processes and operations and should help to improve and/or alter the performance and functionality of mechanical systems by integrating sensors and electronic processing $[19,28]$.

The replacement of mechanical approaches or simple machine technologies with machine technologies in combination with electronics and IT intends to reduce mental and physical strain on humans involved in production processes that can run autonomously. It also allows broadening control functions and integrating learningabilities into production processes in order to increase robustness, reliability, flexibility and cost effectiveness [28].

Robotics as a sub form of mechatronic systems is a relatively new form of engineering, but are already omnipresent components in the most diverse areas of our lives and influence our actions. Robotics is characterized by 
its versatile and flexible applicability - from private households to medical technology and manufacturing processes as Robotics can be understood as "intelligent connection of perception to action" performed by sensors. Sensors help robots to "sense and interact with the changing environment" as well as to gather information, which is then further processed by intelligent algorithms and results in commands that actuate parts of the robots. Robots are characterized by high speed, precision, robustness, power and a long service life. The constant high quality, the unlimited reproducibility as well as the significantly high productivity are fundamental advantages of robots. Robots can provide support by performing non-ergonomic, monotonous, time-consuming and potentially dangerous tasks. Furthermore, robots show no signs of fatigue and apart from maintenance intervals or malfunctions; they are available for continuous operation. They perform handling tasks such as gripping, moving, laying, turning or lifting. Furthermore, some of them already possess the cognitive ability to speak, see and hear which enables them to learn by storing and processing data $[13,28]$.

On the first level, physical machines are involved, which contribute to the expansion of human capabilities with tool character. The second level states that the robot performs activities autonomously using algorithms that modify themselves independently. The highest degree of autonomy occurs when a robot can act in a human-like manner using artificial intelligence [10].

The interaction of robots with humans plays an increasingly important role, both in industrial processes as well as in service contexts. In this context, a distinction is made between three types. On the first level, the so-called coexistence, humans and robots are in the same workspace at the same working time. The subsequent level of cooperation is extended by a common goal. The highest degree of interaction is achieved in collaboration, where man and robot are connected by close joint action. In addition, it is common in practice for several robots to interact together to perform tasks that cannot be performed by a single robot [3].

The definition and improvement of the so-called humanmachine interaction is a complex field of growing research interest and might notice e.g. decision-making and cognitive processes, modelling of human performance, allocation sharing and job design, intelligent interfaces, human operator support, work organization, and selection and training criteria $[3,10,13,28]$. Also on social and psychological aspects of human and robot interaction that correlate with aspects of human resource management and business ethics [10]. The growing application of robots, their technological development and a growing cooperation between men and robots require a dynamic adaptation of working environments and standards.

\subsection{Theoretical Background on Production Management}

The focus of production or operations management are all processes around the combination of production factors for the operational production of goods and services considering the economic principle. The main tasks are the planning, management and control of the targeted transformation of objects in terms of quality, quantity and dimensions. Ecological, economic and employee-related aspects are considered [17].

The main influencing factors on production are time, customer, costs, quality and flexibility. With regard to the time aspect, the focus is on increasing productivity and thus optimizing throughput, research and development, replenishment and reaction times. On the customer side, the aim is to increase the logistical performance for the customer by means of high availability of goods and the best possible delivery service. In addition, the company is trying to expand customer benefits through an individualised product range and to bind customers to the company. Together this leads to increased satisfaction, which has a positive effect on sales and profits. Furthermore, it is essential for companies to reduce elementary costs in order to maintain or increase their profit margin. Cost optimisation is becoming increasingly important, especially in the production area, due to the constantly increasing pressure to maximise efficiency. The objectives of the quality aspect refer to the products of a company with regard to their innovation, durability and reliability. In addition, a high degree of flexibility in production must be aimed for. This refers to the reaction time with regard to internal and external influencing factors, especially in the event of fluctuations in demand [17].

The requirements and challenges in production are also changing fundamentally with the progress of the fourth industrial revolution. The integration of the essential elements of the industry 4.0 such as Big Data and analytics, autonomous robots, simulations, system integration, IoT, cyber security, clouds, additive manufacturing and augmented reality potentially drastically transform existing production processes, logistics, handling of resources as well as integration of humans into workflows and processes. The Smart Factory is one form of enterprise for implementing these factors. Here, processes are increasingly standardized and mechatronic systems are increasingly used instead of classic machine elements. There is already a large number of autonomous production processes that would be unthinkable without the use of robots. They mainly take over tasks like transport, assembly and control of production material. Changes in production management might also lead to a need of learning new skills and capabilities [9, 14, 25, 29, 35].

\subsection{Theoretical Background on Human Resources}

Human resources management, as a further subarea of business administration, deals with the production factor labour. The tasks relate to design and administration and are both personnel and social in nature. Managers and the human resources department pursue the common goal of managing, directing and controlling the personnel considering the needs of the employees and the company [7].

A fundamental trend that is shaping human resources management is demographic change. The shift in the age structure in society towards a higher average age is influenced by the birth and death rates as well as immigration and emigration. This demographic development poses new 
challenges, especially for the working world, especially in developing countries. Human resources management focuses on the increase in the average retirement age, the lack of junior staff, dealing with fluctuation, migration and workplace health promotion [5].

In Germany alone, there is a shortage of more than 1.2 million skilled workers, according to forecasts, there will already be three million by 2030 . This deficiency is one of the greatest critical success factors and, as a brake on growth, has an impact on economic development. An important operational task for human resources management is therefore the long-term securing and retention of skilled workers. This includes, among other things, creating and ensuring attractive working conditions, for example through a fixed income, high management quality, an open-ended employment contract and opportunities for professional development $[21,30]$.

Besides "classical" aspects of occupational health and safety such as counteracting loss of productivity as well as the impairment of performance and chronic diseases and to increase employee motivation, further issues related to change working environments in the industry 4.0 might arise. Human resource managers need to consider adaptation and innovation of occupational health and safety systems in order to meet these new requirements $[2,8]$.

In addition, the education system has undergone many changes in the past. New qualification profiles and competence requirements have emerged, particularly because of the ongoing digitalisation, automation and globalisation in the course of industry 4.0. These new educational contents are increasingly being addressed both in school education and in the world of work, particularly in human resources development. However, pose questions how to qualify elderly workers according to the new requirements of the emerging complex knowledge-intensive work processes that need technological and robotic assistance $[31,34,38]$.

Accompanying the expected transformational change of industrial processes lead to new aspects to be considered by human resource managers. For instance, questions of reeducation, development of new skills of workers that collaborate with robots as well as anti-discrimination matters might arise $[18,28]$.

\section{EMPIRICAL STUDY}

As part of this paper, a written, partially open survey was conducted using the online platform 'Survey Monkey' to collect data. This type of survey was chosen to quickly reach a large number of people regardless of location, to give respondents enough time to answer and to provide anonymity. The only condition for participation in the 'Robotics in the World of Work' survey was employment. The intention was to receive a cross-sectoral general view on the use of robotics and its possible effects on labour. To ensure this criterion, the online link was sent directly to personal contacts of the researchers, which covers the parts of the area of the federal state in Germany the questionnaire comprises ten mandatory questions, which had to be answered within one week.

In order to be able to make a basic classification, personal details such as age, school education and the sector of employment were asked at the beginning. This resulted in a response of 88 persons with a very broad range.

Besides finding out to which extent robots are already part of people's work settings, this study also tries to get an insight in people's perceptions and feelings of robots. It might deliver useful guidelines for decision-makers. To consider machine ethic aspects is important for engineers and (human resource) managers in order to ensure a successful implementation of machine technologies into production processes and to stimulate supporting measures to ensure positive social outcomes [9].

\subsection{Empirical Results on Business Ethics}

One aspect of business ethics is the fear of robots replacing jobs. In the questionnaire, the employees were asked to indicate whether and why they have this fear regarding their job or not. $9.1 \%$ of the respondents said that they were afraid of losing their jobs within the next twenty years. The arguments are that companies can save costs in the end by using robots and that the job profiles will change as industry 4.0 progresses. Especially activities with high repetition frequency and low complexity are affected by this change.

Five of the eight respondents who answered 'yes' are active in the service industry. One possible justification for their assessment is that, for example, in banking, administrative activities or travel booking, algorithms are increasingly being used to initially facilitate these activities and finally completely replace them.

Assessment of the danger that robots will be superior to human intelligence

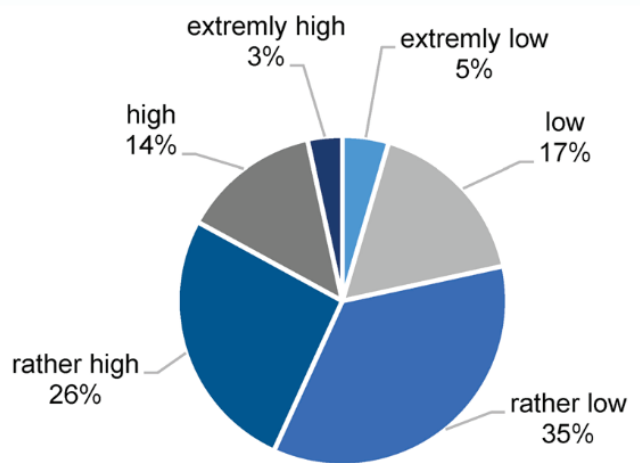

Figure 2 Danger that robots will be superior to human intelligence (own illustration)

In contrast, 90.9 percent of the participants are not afraid of losing their jobs. The main argument is that there are many individual activities where factual and often quick action and decisions are required. Furthermore, expertise, experience, creativity and empathy are often required to accomplish tasks. Some of the interviewees are of the opinion that technology is not yet mature in some areas or that investments are not profitable. Others justify their non- 
existent fear by the fact that the use of robots creates new jobs or that they are about to retire.

Business ethics also deals with the question of whether there is a danger that robots will be superior to human intelligence. Fig. 2 illustrates, in percentage terms, the assessment of the risk by the employees from extremely low to extremely high.

In the survey, 54 out of 88 employees, well over half, classified the risk as medium, with a tendency towards low risk. Since the risk cannot be fully assessed, the assessment of the employed persons is nevertheless divided.

For example, the proportion of those who assess the risk as low to very low (19 persons) is only slightly higher than the proportion of those who assess it as high to very high (15 persons).

A detailed examination of the age structure, educational attainment and sector does not reveal a clear trend in terms of the answers. This can be explained by the fact that it is a vision and depends on the range of actions and personal feelings of the individuals.

\subsection{Empirical Results on Mechatronics}

In mechatronics, the application of robotics is discussed. In order to find out whether and to what extent this is common in companies or directly at the workplace of the participants, a partially open question was asked on this subject. The interviewees had the possibility to choose between use and no use and then to indicate in categories in which areas robots are used or not used for which reasons. The specified areas were assembly, transport, service, packaging and quality control.

$21.6 \%$ of the respondents stated that robots were used in their assembly operations, for example in processes such as welding, milling or screwing. In transport, for example picking up, turning or setting down, robotics is used in $14.8 \%$ of cases. The third area of application is the packaging sector with $12.5 \%$, which includes processes such as picking or gluing. At $10.2 \%$, quality control is supported by robots during activities such as scanning, measuring or weighing. Only a small proportion of $4.6 \%$ use them for service tasks such as cleaning or repairing.
On the other hand, 44 respondents stated that they do not use robots, firstly because human thinking and knowledge is required and secondly because human experience is necessary. 42 indicated that the responsibility and decisionmaking power could only lie with humans. For almost one third of the workforce, the need for empathy or creativity is a justification. Fewer than eight people are of the opinion that robots are not used because of high investment, lack of profitability, immature technology, safety aspects or insufficient legislation.

Due to the fact that the respondents had the possibility to choose several answer options, the result is that a total of 56 times "Yes, in the range..." and 210 times "No, because..." were selected. This shows that in companies the reasons against the use of robotics clearly predominate. This is particularly the case in health and social services and the service sector, this contrasts with results from other studies see a huge potential for the use of AI and robots in health and social services.

In the further course of the questionnaire it was necessary to prioritize in which of six predefined areas the use of robots, according to the personal opinion of the respondents, brings the greatest benefit. In the evaluation, the area with the highest percentage of respondents prioritizing was selected for each priority level. Thus, $69.3 \%$ placed industry in first place, followed by medicine with $37.5 \%$ in second place. In the middle field are the transport sector with $31.8 \%$ and trade with $28.4 \%$. The respondents see a smaller advantage of robotics in the education sector with $35.2 \%$.

The service sector was classified by $33 \%$ as the area where robotics brings the least benefit. The clear prioritisation of industry in the first place confirms the previous findings that robotics can be implemented and used more easily and effectively in this sector than in other sectors. Potentials in medicine are probably seen in precision, research and permanent applicability. The prioritisation of transport in third place is also related to the further development of topics such as autonomous driving. The human factor plays an indispensable role in the areas of trade, education and services, so that robots are seen as having less advantage in these areas.

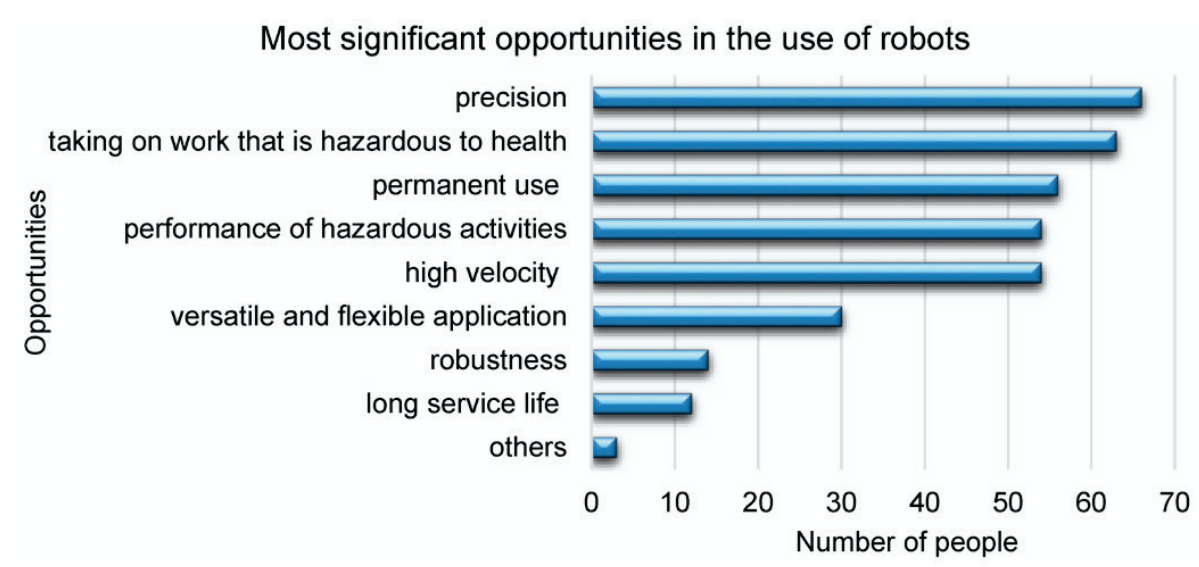

Figure 3 Most significant opportunities in the use of robots (own illustration) 


\subsection{Empirical Results on Production Management}

There are many advantages and opportunities in the use of robots in the working world. The respondents were asked to select the four most significant opportunities in their opinion. Fig. 3 shows the results of this question.

$75 \%$ of all respondents stated that the precise operation of a robot is of great importance. This was followed by $71.6 \%$ who took on work that was harmful to their health. In addition, $63.6 \%$ of all respondents see the permanent use of robots as an opportunity. With $61.4 \%$ each, high speed and the execution of hazardous activities also play a more important role. It can be deduced from this that employed persons see opportunities in those areas in which they are clearly inferior to robots. In many areas, robots are able to work faster and more precisely than humans with consistently high productivity [11]. As a result, production targets of the factors time, customer, costs, quality and flexibility can be better implemented. Furthermore, they see a benefit in the fact that robots perform activities that are harmful to health, dangerous or monotonous. As a result, employees are relieved of physical strain, can focus on other activities and develop personally or dedicate themselves to tasks that require creativity or human attention, for example.

On the other hand, there are also some risks and disadvantages associated with the use of robots. Fig. 4 shows the answers to the question of the four most significant risks.

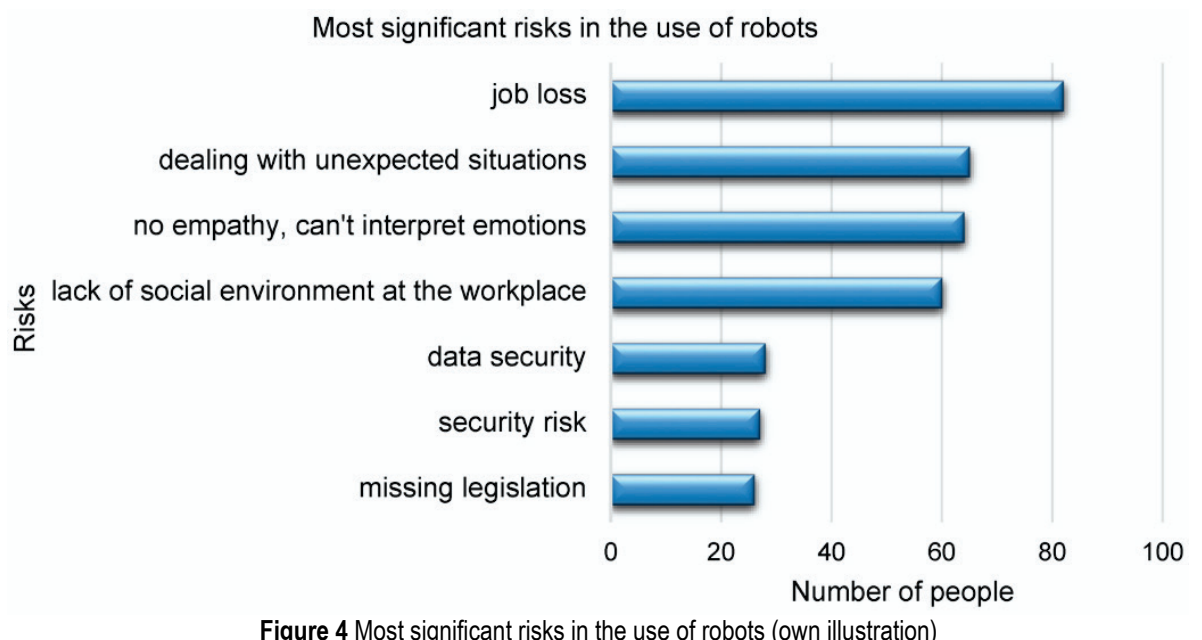

The risk of losing one's job due to a robot was rated as high by 82 of the 88 respondents. In contrast, only eight of the respondents had previously stated that they were afraid of losing their jobs within the next twenty years. This striking deviation shows that the respondents assume that a large number of workplaces could be replaced by robots, but that they themselves are not affected for the reasons described in point 4.2. This corresponds to the statements of various scientific sources that robots replace jobs depending on the activity, but in return, new jobs are created. These include activities that require, for example, responsibility, cognitive skills as well as training to foster interaction or collaboration between humans and robots $[8,15,27]$.

In addition, 65 respondents perceive dealing with unexpected situations as risky. This shows the necessity of security systems, legal regulations, wide-ranging algorithms and clearly defined decision-making leeway [8].The rate of more than two thirds indicates that the respondents do not yet consider these requirements to be sufficiently fulfilled.

Other risks that were classified as significant are the lack of empathy of robots and the decline of the social environment at the workplace. In this context, it is clear that the idea of a workplace for the future is not sufficiently tangible for employees. Many have the image of a robotheavy work environment in which humans play a secondary role.

\subsection{Empirical Results on Human Resources}

Challenges for human resources management are in particular the lack of skilled workers, demographic change and health aspects. As already described before, one solution is the use of robotics. This is also accompanied by changes in the educational system. In order to find out the attitude of the employees towards this approach, it was asked whether they could imagine working hand in hand with a robot. $44.3 \%$ answered that they could imagine this cooperation. The arguments reflect many of the advantages and opportunities already mentioned. These are the increase of effectiveness and efficiency, the facilitation of work and relief especially from monotonous and dangerous tasks, as well as support in physically demanding activities. In this way, man and robot complement each other positively in the long term. Workers are able to work longer due to the health relief, which is one way to deal with the challenge of demographic change. Another reason is the need to cover the lack of capacity, which also results from the shortage of skilled workers. Some of the interviewees also stated that they already work with robots and that they could imagine doing so in the future, if human contact is maintained.

In contrast, $55.7 \%$ cannot imagine working with a robot. Here, too, the many risks and disadvantages characterize the arguments of the respondents. In particular, the lack of interpersonal relationships and the lack of a social environment were elementary reasons for this. In addition, 
some of the employees carry out changing activities for which the use of a robot is still hardly conceivable. Often employees bear a lot of responsibility and have to make decisions, some of which are ethical and require experience. Since this requires empathy, among other things, the use of robots is currently not possible in many areas. Some also stated that they still lack the imagination to work with a robot.

These answers show schematically why robots have so far been used in such a small range in companies and only in specific areas. Looking at the sector of those who answered "yes" from this point of view, it is noticeable that they are mainly active in industry and respondents who answered "no" come primarily from the administrative, service and social sectors.

\section{CONCLUSION}

The fourth industrial revolution is changing the world. Robots, big data and artificial intelligence are the key technologies and the basis of important innovations for future development of economies and societies. Their broad utilisation might bring disruptive changes to economies and societies. A clear trend whether robotics will lead to job loss or job creation, still needs to be further analysed and might depend e.g. on complex circumstances such as level of uncertainty, state of economic development, education and training as well as the industry sector.

This study contributes to research on robotics and its possible impacts on human labour by integrating aspects of business ethics, mechatronics, production and human resource management. By executing an online survey among German employees from different sectors experiences with and attitudes towards robotics were collected in order to get an insight into crucial aspects to be considered when integrating robotics into working processes.

Even though, the findings cannot be generalized as the number of survey participants was limited, the results reflect discussions, fears and different stages of utilisation of robots in production processes that were to be found in studies from other countries [22, 24, 26]. Possible influences of robotics on human labour are depending on a multitude of factors and require an individual and situational case decision. In addition to the purely technical aspects of feasibility, social and ethical aspects are moving more into focus with the increasing utilisation of robotics. Besides technological decisions to be made by managers in order to adapt and improve their production processes to the use of robots, human resource managers should be integrated into these processes as well. Future research could focus on how to create learning opportunities for workers, but also be part of dealing with questions of how to develop the interface between humans and machines by acknowledging ethical and social standards.

\section{Notice}

The paper will be presented at MOTSP $2021-12^{\text {th }}$ International Conference Management of Technology - Step to Sustainable Production, which will take place in Poreč/Porenzo, Istria (Croatia), on September 8-10, 2021. The paper will not be published anywhere else.

\section{REFERENCES}

[1] Anderson, M. \& Anderson, S. L. (2020). Machine ethics: Creating an ethical intelligent agent. Machine Ethics and Robot Ethics. Routledge, 237-248. https://doi.org/10.4324/9781003074991-22

[2] Badri, A., Boudreau-Trudel, B., \& Souissi, A. S. (2018). Occupational health and safety in the industry 4.0 era: A cause for major concern? Safety science, 109, 403-411. https://doi.org/10.1016/j.ssci.2018.06.012

[3] Bartneck, C. \& Forlizzi, J. (2004, September). A designcentred framework for social human-robot interaction. In ROMAN 2004. $13^{\text {th }}$ IEEE international workshop on robot and human interactive communication (IEEE Catalog No. 04TH8759), 591-594.

[4] Belisario, J. S. M., Jamsek, J., Huckvale, K., O'Donoghue, J., Morrison, C. P., \& Car, J. (2015). Comparison of selfadministered survey questionnaire responses collected using mobile apps versus other methods. Cochrane database of systematic reviews, (7). https://doi.org/10.1002/14651858.MR000042.pub2

[5] Bieling, G., Stock, R. M., \& Dorozalla, F. (2015). Coping with demographic change in job markets: How age diversity management contributes to organisational performance. German Journal of Human Resource Management, 29(1), 530. https://doi.org/10.1177/239700221502900101

[6] Bonciu, F. (2017). Evaluation of the impact of the 4th industrial revolution on the labor market. Romanian Economic and Business Review, 12(2), 7-16.

[7] Boxall, P., Purcell, J., \& Wright, P. M. (2007). Human resource management. The Oxford handbook of human resource management.

[8] Bragança, S., Costa, E., Castellucci, I., \& Arezes, P. M. (2019). A brief overview of the use of collaborative robots in industry 4.0: human role and safety. Occupational and environmental safety and health, 641-650. https://doi.org/10.1007/978-3-030-14730-3_68

[9] Brundage, M. (2014). Limitations and risks of machine ethics. Journal of Experimental \& Theoretical Artificial Intelligence, 26(3), 355-372. https://doi.org/10.1080/0952813X.2014.895108

[10] Demir, K. A., Döven, G., \& Sezen, B. (2019). Industry 5.0 and human-robot co-working. Procedia computer science, 158, 688-695. https://doi.org/10.1016/j.procs.2019.09.104

[11] Fu, X. M., Bao, Q., Xie, H., \& Fu, X. (2021). Diffusion of industrial robotics and inclusive growth: Labour market evidence from cross country data. Journal of Business Research, 122, 670-684. https://doi.org/10.1016/j.jbusres.2020.05.051

[12] Fragapane, G., Ivanov, D., Peron, M., Sgarbossa, F., \& Strandhagen, J. O. (2020). Increasing flexibility and productivity in Industry 4.0 production networks with autonomous mobile robots and smart intralogistics. Annals of operations research, 1-19. https://doi.org/10.1007/s10479-020-03526-7

[13] Helms, E., Schraft, R. D., \& Hagele, M. (2002).rob@work: Robot assistant in industrial environments. Proceedings of the $11^{\text {th }}$ IEEE International Workshop on Robot and Human Interactive Communication, 399-404. https://doi.org/10.1109/ROMAN.2002.1045655

[14] Hofmann, E. \& Rüsch, M. (2017). Industry 4.0 and the current status as well as future prospects on logistics. Computers in industry, 89, 23-34. https://doi.org/10.1016/j.compind.2017.04.002

[15] Huber, A. \& Weiss, A. (2017, March). Developing humanrobot interaction for an industry 4.0 robot: How industry 
workers helped to improve remote-HRI to physical-HRI. In Proceedings of the Companion of the 2017 ACM/IEEE International Conference on Human-Robot Interaction, 137138. https://doi.org/10.1145/3029798.3038346

[16] Jiang, S. \& Arkin, R. C. (2015, October). Mixed-initiative human-robot interaction: definition, taxonomy, and survey. 2015 IEEE International Conference on Systems, Man, and Cybernetics, 954-961. https://doi.org/10.1109/SMC.2015.174

[17] Kumar, S. A. \& Suresh, N. (2006). Production and operations management. New Age International.

[18] Kurt, R. (2019). Industry 4.0 in terms of industrial relations and its impacts on labour life. Procedia Computer Science, 158, 590-601. https://doi.org/10.1016/j.procs.2019.09.093

[19] Kuru, K. \& Yetgin, H. (2019). Transformation to Advanced Mechatronics Systems within New Industrial Revolution: A Novel Framework in Automation of Everything (AoE). IEEE Access, 7, 41395-41415. https://doi.org/10.1109/ACCESS.2019.2907809

[20] Kyrarini, M., Lygerakis, F., Rajavenkatanarayanan, A., Sevastopoulos, C., Nambiappan, H. R., Chaitanya, K. K., ... \& Makedon, F. (2021). A Survey of Robots in Healthcare. Technologies, 9(1), 8. https://doi.org/10.3390/technologies9010008

[21] Lemmer R. (2014). Auf Vier geht's los. Personalmagazin, Nr. $12,48-51$.

[22] Lloyd, C. \& Payna, J. (2019). Rethinking country effects: robotics, AI and work futures in Norway and the UK. New Technology, Work and Employment, 34(3), 208-225. https://doi.org/10.1111/ntwe.12149

[23] Martin, E. (2006). Survey questionnaire construction. Survey methodology, 2006, 13.

[24] Mfanafuthi, M., Nyawo, J., \& Mashau, P. (2019). Analysis of the impact of artificial intelligence and robotics on human labour. Gender and Behaviour, 17(3), 13877-13891.

[25] Min, H. (2010). Artificial intelligence in supply chain management: Theory and applications. International Journal of Logistics Research and Applications, 13(1), 13-39. https://doi.org/10.1080/13675560902736537

[26] Morikawa, M. (2017). Firm's expectations about the impact of $\mathrm{AI}$ and Robotics. Evidence from a survey. Economic Inquiry, 55(2), 1054-1063. https://doi.org/10.1111/ecin.12412

[27] Moor, J. H. (2020). The Mature, Importance, and Difficulty of Machine Ethics. Machine Ethics and Robot Ethics, 233-236. Routledge. https://doi.org/10.4324/9781003074991-21

[28] Ollero, A., Boverie, S., Goodall, R., Sasiadek, J., Erbe, H., \& Zuehlke, D. (2006). Mechatronics, robotics and components for automation and control: IFAC milestone report. Annual Reviews in Control, 30(1), 41-54. https://doi.org/10.1016/j.arcontrol.2006.02.002

[29] Prinz, C., Morlock, F., Freith, S., Kreggenfeld, N., Kreimeier, D., \& Kuhlenkötter, B. (2016). Learning factory modules for smart factories in industry. 4.0. Procedia CiRp, 54, 113-118. https://doi.org/10.1016/j.procir.2016.05.105

[30] Rößler M. (2015). Maschine fordert Mensch heraus. Personalmagazin, Nr. 12, 18-21.

[31] Sivathanu, B. \& Pillai, R. (2018). Smart HR 4.0-how industry 4.0 is disrupting HR. Human Resource Management International Digest. https://doi.org/10.1108/HRMID-04-2018-0059

[32] Taherdoost, H. (2016). How to design and create an effective survey/questionnaire: A step by step guide. International Journal of Academic Research in Management (IJARM), 5(4), $37-41$.

[33] Toorajipour, R., Sohrabpour, V., Nazarpour, A., Oghazi, P., \& Fischl, M. (2021). Artificial intelligence in supply chain management: A systematic literature review. Journal of Business Research, 122, 502-517. https://doi.org/10.1016/j.jbusres.2020.09.009

[34] Vaganova, O. I., Smirnova, Z. V., Gruzdeva, M. L., Chaykina, Z. V., \& Ilyashenko, L. I. (2019). Development of training content for master students in course" mechatronics and robotics" at the University. Amazonia Investiga, 8(22), 694700 .

[35] Vaidya, S., Ambad, P., \& Bhosle, S. (2018). Industry 4.0-a glimpse. Procedia manufacturing, 20, 233-238. https://doi.org/10.1016/j.promfg.2018.02.034

[36] Webster, C. \& Ivanov, S. (2020). Robotics, artificial intelligence, and the evolving nature of work. Digital Transformation in Business and Society. Palgrave Macmillan, Cham, 127-143. https://doi.org/10.1007/978-3-030-08277-2_8

[37] Webster J. \& Watson R. (2002). Writing a Literature Review. MIS Quarterly, Nr. 2, 13-15.

[38] Wolf, M., Kleindienst, M., Ramsauer, C., Zierler, C., \& Winter, E. (2018). Current and Future Industrial Challenges: Demographic Change and Measures for Elderly Workers in Industry 4.0. Annals of the Faculty of Engineering Hunedoara - International Journal of Engineering, 16(1).

\section{Authors' contacts:}

Daniela Ludin, Prof. Dr.

Heilbronn University of Applied Sciences,

Ziegeleiweg 4, 74523 Schwäbisch Hall, Germany daniela.ludin@hs-heilbronn.de

Wanja Wellbrock, Prof. Dr.

(Corresponding author)

Heilbronn University of Applied Sciences,

Ziegeleiweg 4, 74523 Schwäbisch Hall, Germany

wanja.wellbrock@hs-heilbronn.de

\section{Erika Müller}

Heilbronn University of Applied Sciences,

Ziegeleiweg 4, 74523 Schwäbisch Hall, Germany

erika.mueller@hs-heilbronn.de

Wolfgang Gerstlberger, Prof. Dr.

Tallinn University of Technology,

Ehitajate tee 5, 19086 Tallinn, Estonia

wolfgang.gerstlberger@taltech.ee

\section{Lea Gray}

Heilbronn University of Applied Sciences,

Ziegeleiweg 4, 74523 Schwäbisch Hall, Germany

Sabrina Salat

Heilbronn University of Applied Sciences,

Ziegeleiweg 4, 74523 Schwäbisch Hall, Germany 